\title{
Katı Yakıtlı Bir Kazanda Isı Transferi İyileştirmeleri ve Basınç Farkının Yapay Sinir Ağı ile Modellenmesi
}

\author{
Aydın ÇITLAK ${ }^{1 *}$, Ahmet Beyzade DEMIRPOLAT ${ }^{1}$, Mehmet DAŞ ${ }^{2}$ \\ ${ }^{1}$ Fırat Üniversitesi Mühendislik Fakültesi Makine Mühendisliği Bölümü, Elazığg, Türkiye \\ ${ }^{2}$ Erzincan Binali Yıldırım Üniversitesi İliç Dursun Yıldırım Meslek Yüksekokulu, İliç, Erzincan, Türkiye \\ *1 acitlak@firat.edu.tr, ${ }^{2}$ mdas@erzincan.edu.tr
}

Öz: Bu çalışmada, duman borularının çap1 $42 \mathrm{~mm}$, baca çapı $230 \mathrm{~mm}$ ve su giriş ve çıkış çapları $65 \mathrm{~mm}$ olan $125.000 \mathrm{kcal} / \mathrm{h}$ 1S1 kapasiteli katı yakıtlı kazanda, 4 farklı tipte şerit türbülatör kullanılarak 1S1 transferinin iyileştirilmesi incelenmiştir. Kazandaki duman borularının tümüne yerleştirilen türbülatörlerle deneyler yapılmıştır. İlk olarak içerisine türbülatör yerleştirmeden deneyler yapılmıştır. İkinci adımda ise duman boruları içerisine türbülatörler yerleştirerek her tip için ayrı ayrı deneyler yapılmış ve isı transferi hesaplanmıştır. Deneylerde fan debisi damper yardımıyla değiştirilerek Reynolds sayısı 1800 ile 2800 arasındaki değerlerde hesaplamalar yapılmıștır. Isı transferi iyileștirmesi için yapılan türbülatörlü deneyler, türbülatörsüz deneylere göre 1sı transferinde en az \% 44, en fazla \% 82 oranında artış sağlanmıştır. Hesaplamalar sonucu elde edilen basınç farkı değerleri için yapay sinir ağı (YSA) kullanılarak tahminsel bir model elde edilmiştir. Elde edilen modelin hata analizleri yapılmış ve basınç değerlerini başarılı bir şekilde tahmin ettiği gösterilmiştir.

Anahtar kelimeler: Isı transferi, türbülatör, basınç fark1, yapay sinir ağı

\section{Heat Transfer Improvements in a Solid Fueled Boiler and Modeling of Pressure Differences by Artificial Neural Network}

\begin{abstract}
In this study, the improvement of heat transfers by using 4 different types of strip turbulators in solid fuel boiler was investigated. The smoke pipes of the boiler used are $42 \mathrm{~mm}$ in diameter, the chimney diameter is $230 \mathrm{~mm}$ and the water inlet and outlet diameters are $65 \mathrm{~mm}$ and the heat capacity is $125,000 \mathrm{kcal} / \mathrm{h}$. Experiments have been carried out with turbulators placed in all smoke pipes in the boiler. Firstly, experiments were carried out without inserting a turbine. In the second step, turbulators were placed in smoke pipes for each type of experiments and heat transfer was calculated. In the experiments, the fan flow rate was changed with the help of damper and the Reynolds number was calculated between 18000 and 28000 . For turbine heat exchanger experiments, turbulence tests were carried out and heat transfer was increased by at least $15 \%$ and maximum $82 \%$. As a result of the calculations, a predictive model was obtained by using artificial neural network (ANN) for the pressure difference values. The obtained model has been analyzed for error and has been shown to predict the pressure values successfully.
\end{abstract}

Key words: Heat transfer, turbulator, pressure difference, artificial neural network

\section{Giriş}

Isı değiștiricilerinde amaç maksimum 1sı çekebilmektir. Bu da 1sı transferinin iyileștirilmesiyle mümkündür. Isı transferini iyileştirmek için kullanılan aktif veya pasif yöntemde amaç ısı tasınım katsayısını artırmaktır. Isı tasınım katsayısını artırmanın en iyi yolu türbülansın artırılmasıdır. Çünkü 1sı geçişi türbülanslı akışta fazla, laminar akışta daha az olmaktadır. Laminar akışta 1sı geçişinin azalmasının nedeni akışkan partiküllerinin katmanlar halinde birbiri üzerinden akması sonucu isı geçişi olumsuz etkilenmektedir. Türbülanslı akıșta ise türbülans sebebiyle katmanlar oluşmamakta ve akışkan parçacıkları arasındaki ısı geçişi artmaktadır. Bilindiği gibi tam gelişmiş akışta oluşan sınır tabaka ve alt sınır tabaka içerisindeki hız dağılımı, akışkanın tasınım katsayısını önemli oranda değiştirmektedir. Türbülans düzeyi arttıkça 1S1 geçişi de artacaktır. Özellikle endüstriyel tip kazanlarda ve kalorifer kazanlarında 1sı transferinin, dolayısıyla kazan veriminin artıılması için türbülatör (türbülans üretici) kullanımı oldukça yaygınlaşmıştır. Türbülatörlerden elde edilen sonuçların yıllık enerji

\footnotetext{
* Sorumlu yazar: acitlak@ firat.edu.tr. Yazarların ORCID Numarası: ${ }^{1}$ 0000-0002-6837-4178, ${ }^{1} 0000-0003-2533-3381,{ }^{2} 0000-0002-4143-$ 9226
} 
maliyetlerinin düşürülmesi açısından ciddi boyutlarda olması hem mühendisleri hem de imalatçıları yeni türbülatör modelleri arayışı içerisine itmiştir. Böylece bu alanda çalışmalar hız kazanmış ve en uygun türbülatör geometrisi ve malzemesi için gerek deneysel gerek sayısal birçok çalışmalar yapılmıştır [1-2].

Bir boru içindeki 1sı transferi ve türbülanslı hava akışındaki girdabın etkisi deneysel olarak Sparrow ve Chaboki [3], tarafından incelenmiştir. Girdap olmayan boru akışındaki ısı transferi ile karşılaştırdıklarında girdap eleman içeren borulardaki isı transferinin dikkate değer şekilde daha büyük olduğunu tespit etmişlerdir. Verma ve ark., [4], çalışmalarında oluklu ve oluklu olmayan borular kullanılarak önerilen fabrikasyon 1sı değiştiricinin 1sı transfer performansını karşılaştırmışlardır. Boruların boyu ve çapı sırasıyla $25.4 \mathrm{~mm}$ ve $2000 \mathrm{~mm}$ 'dir. Yazarlar ayrıca 1sı transfer katsayısını, Nusselt sayısını ve Reynolds sayısını tahmin etmek için yapay sinir ağını (YSA) modellemişlerdir. Yazarlar maksimum 1sı geçiş katsayısı ve Nusselt sayısı değerini sarmal şekilli oluklu boru kullanılmış 1sı değiştirgecinde elde etmişlerdir. Neuber ve ark., [5], türbülanslı saf hidrojen difüzyon alevi üzerine çalışmalar yapmışlardır. Yakıcıda türbülanslı alevin modellenmesinde standart k- $\varepsilon$ modeli kullanmışlardır ve bu modelin iyi akış tahminleri verdiğini kaydetmişlerdir. Boru girişinde düzgün sıralı enjektörlü türbülans üretici bulunan 1sı değiştiricilerinde, enjektörlerin ısı geçişi ve basınç düşümüne etkisi deneysel olarak Yıldız ve Çakmak [6], tarafından incelenmiştir. Çeşitli kanatçık düzenlemeleri kullanılarak, hava soğutmalı kondenselerdeki ve sıvılı soğutuculardaki ısı transferi artışları Lozza ve Merlo [7], tarafından araştırılmıştır. Çalışmada 15 adet aynı tür boru fakat değişik kanatçık yüzey geometrisine (düz veya dalgalı) sahip kanatçıklar kullanılmıştır. Kullanılan kanatçıkların 1sı değiştiricisinde etkili olduğu görülmüştür. Yıldız ve ark. [8], eş merkezli çift borulu bir 1sı değiştiricisine yerleştirilen kıvrımlı şeridin 1sı transferine ve basınç kaybına etkisi incelenmiştirler. Deneyler hem eş yönlü, hem de karşıt akış durumları için yapılmıştır. Çift borulu hava soğutmalı sistemde 1sı transferi, tüp içerisine kıvrımlı şerit şeklinde türbülatör yerleştirilerek \%100 artırılmıştır. Zaherzadeh ve Jagadish [9], dönmeli akış üreticisi olarak kendi ekseni etrafında dönen palet karıştırıcılar kullanmışlardır. Araştırmacılar, iki disk arasına düz paletler yerleştirerek elde ettikleri çark seklindeki dönmeli akış üreticilerini boru girişine yerleştirmişlerdir. Deney sonuçlarına göre dönmeli akış üreticisinin kullanılması ile 1S1 transferinin \%80 civarında arttı $\breve{g ̆}_{1}$ gözlemlenmiştir.

Isı transferi araştırmaları için birçok veri ve formül kullanılmaktadır. Çok fazla verinin işlenmesi ve sonuç elde edilmesi oldukça zaman alıcı ve zahmetli bir iştir. Bu bakımdan birçok veriyi işlemek için çeşitlik hesaplamalı zekâ yöntemleri kullanılmaktadır. Bu yöntemler içerisinde en yaygın olanı yapay sinir ağlarıdır. Yapay sinir ağları 1Sı transferi hakkında yapılan birçok çalışmaya uygulanmıştır. Mayro Rico ve ark. [10], oluklu ve iç tüpleri olan ve gıda endüstrisinde tipik olarak kullanılan bir üçlü eş merkezli borulu 1sı değiştiricideki 1Sı transfer oranını ve basınç düşüşünü doğru bir şekilde tahmin edebilen bir Yapay Sinir Ağları (YSA) modelini oluşturmuşlardır. YSA modelini, 181 deneysel veri kümesini içeren bir veri bankası kullanılarak geliştirmiş ve doğrulamışlardır. YSA konfigürasyonu, sırasıyla birinci ve ikinci katmanda 15 ve 21 nöronlu iki gizli katmanı olan bir ağdan oluşmuştur. YSA sonuçlarının, deneysel verilerle iyi bir uyum içinde olduğu, mutlak ortalama nispi sapmanın (AARD), 1S1 transfer katsayısı için \% 1.91'in altında ve basınç düşüşü için sırasıyla \% 3.82'nin altında olduğu bulmuşturlar.

Bu çalışmanın amacı, üretilen türbülatör tiplerinin katı yakıtlı bir kazandaki ısı transferi üzerindeki etkilerini araştırmak ve isı transferini iyileştirmektir. Bu amaçla, duman borulu kazanlarda boru içeresine değişik tipte türbülatörler geliştirilip yerleştirilmesi suretiyle 1sı transferindeki artış ve basınç kaybı araştırılmıştır. Bu şekilde farklı türbülatölerin 1sı transferine etkileri incelenmiştir. Boru girişine ve boru boyunca türbülatörler yerleştirilerek sönümlenen ve sönümlemeyen akışlar için sonuçlar elde edilmiştir. Sisteme gerekli su ve sıcak dumanın verilmesi için gerekli düzenlemeler yapılmıştır. Duman borusu içinden çekilen hava akımının elde edilmesi için gerektiğinde bir fan kullanılmıştır. Boru yüzeyindeki ve akışkan sıcaklıkları termo elemanlar ile bir kanal seçici ve sıcaklık ölçerler yardımıyla okunmuştur. Sistem üzerinde belirli noktalarda basınç değerleri okunarak basınç kayıpları belirlenmiştir. Elde edilen basınç kayıp değerleri için yapay sinir ağı (YSA) kullanılarak tahminsel bir model geliştirilmiştir. Tahminsel modelin geçerliliğini belirlemek için, ortalama mutlak hata (MAE), kök ortalama karesel hata (RMSE), bağıl mutlak hata (RAE) ve kök bağıl mutlak hata (RRAE) analizleri yapılmıştır. Bu çalışmanın; duman borulu kazanların basınç kayıpları ve tasarımı hakkında yapılacak çalışmalara, YSA yönteminin kullanılarak bazı termofiziksel özellikleri önceden tahmin etmek adına örnek teşkil edebileceği beklenmektedir.

\section{Materyal ve Metot}

\subsection{Deney Seti}

Deneysel çalışmalar, Malatya Mimsan Ltd. Sti. kazan fabrikasında kurulan deney düzeneği ile yapılmıştır. Deney düzeneğinin şematik görünüşü Sekil 1.' de verilmiştir. 


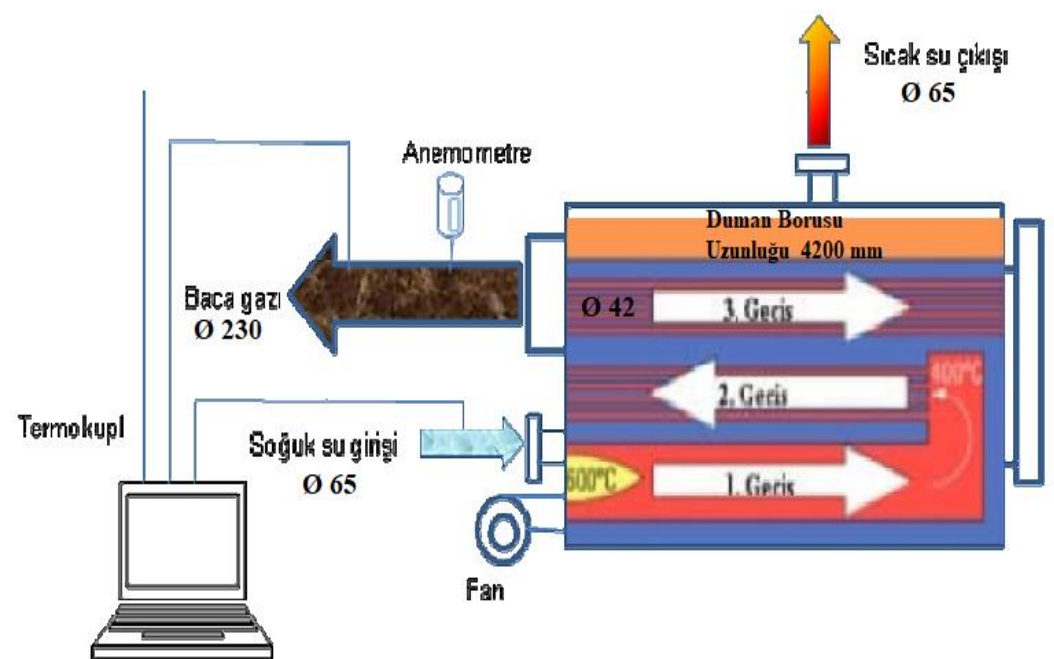

Sekil 1. Deney düzeneğinin şematik görünüşü.

Deney düzeneğinde; sıcak su elde etmek için katı yakıtlı Mimsan marka $125.000 \mathrm{kCal} / \mathrm{h}$ kapasiteli 3 geçişli bir kazan, çeşitli noktalarda sıcaklık ölçen çok girişli bilgisayar kontrollü sıcaklık ölçer, baca gazı hızı için anemometre ve basınç farkı için elektronik fark basınç cihazı kullanılmıştır. Kazanın duman borularının çapı 42 $\mathrm{mm}$, baca çapı $230 \mathrm{~mm}$ ve su giriş çıkış çapları $65 \mathrm{~mm}$ ' dir. Su giriş-çıkısı ve baca gazına yerleştirilen T tipi 0.5 mm teflon izoleli bakır (Cu-Cons) 1sıl çiftlerle ölçülmüştür. Sıcaklık ve basınç ölçümleri için 32 kanallı ELIMMKO marka dijital tarayıcı kullanılmıştır. Bacaya takılan anemometre ile baca gazı hızı ölçülmüştür. Ayrıca 1sıtılan suyun deney sisteminde dolaşması için sirkülasyon pompası ve dolasan suyun debisini ölçmek için flanşlı tip manyetik rotametre boruya takılmıştır. Isı transferini attırmanın yollarından biri sistemde duman boruları içine türbülatörler yerleştirmektir. Yapılan deneylerde 4 farklı tipte toplam 8 türbülatör kullanılmıştır. Ayrıca tüm Re sayıları için türbülatörsüz olarak da ölçüm alınmıştır. Yakıt olarak ceviz boy Rus linyit kömürü kullanılmıştır. Deney setine ait resimler Şekil 2 ve Şekil 3' de verilmiştir.

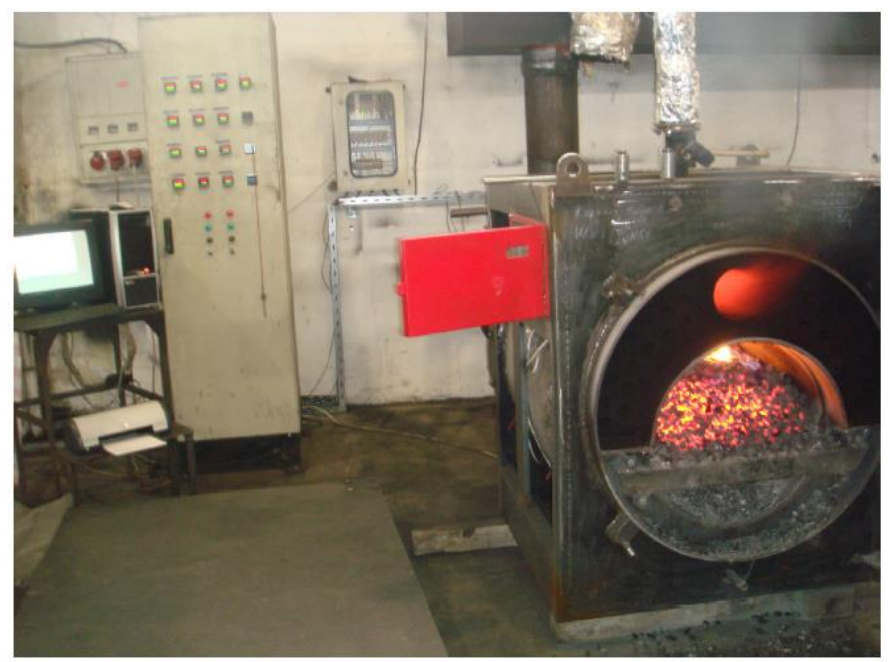

Şekil 2. Deneylerde kullanılan kazan ve otomasyon sistemi

Türbülatörler 2 mm lik sacdan üretilmiştir ve ısıtılarak preste şekillendirilmiştir. Türbülatörler kıvrımlı ve dalgalı olmak üzere iki tip üretilmiştir. Tam boy türbülatörlerin boyu $90 \mathrm{~cm}$ dir. Deneysel çalışmada kullanılan türbülatörler tam boy olarak imal edilmiş olup bu türbülatörler kullanılarak deneysel veriler elde edilmiştir. (Şekil $3)$. 

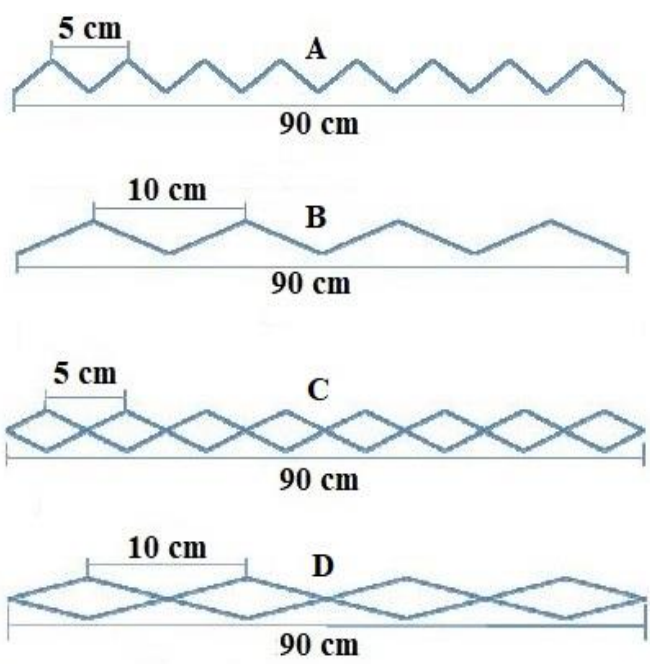

Şekil 3. Türbülatör tipleri (A: Sık dalgalı tam boy, B:Seyrek dalgalı tam boy, C: Sık kıvrımlı tam boy, D: Seyrek kivrımlı tam boy)

\subsection{Hesap Yöntemi}

Kazanda kullanılan fan, damper yardımıyla $1650 \mathrm{~m}^{3} / \mathrm{h}, 1050 \mathrm{~m}^{3} / \mathrm{h}$ ve $700 \mathrm{~m}^{3} / \mathrm{h}$ hava debisi sağlamaktadır. Kazan duman borusu sayısı 34 adettir. $\mathrm{D}_{\mathrm{i}}$ çap $12 \mathrm{~mm}$ olan her bir duman borusundan geçen hacimsel debi, debinin duman borusu sayısına oranıyla tespit edilmiş̧ir. Re sayısı Denklem (1) yardımıyla bulunmuştur [11].

$$
\operatorname{Re}=\frac{U \cdot D_{i}}{v}
$$

Denklem (1)'de $v$ havanın kinematik viskozitesi, $\mathrm{D}_{\mathrm{i}}$ borunun iç çapı, $\mathrm{U}$ duman borusu içindeki ortalama hızdır. Çalışmada $R e=18000-28000$ aralığında 3 farklı debide ölçümler yapılmıştır.

Boru içindeki sıcak duman gazından oluşan ve boru dış yüzeyindeki suya geçen 1sı miktarı $\left(\mathrm{Q}_{1}\right)$ Denklem (2)'den faydalanarak bulunmuştur [12]. Bu 1sı miktarı aynı zamanda boru içindeki suyun 1sı miktarına $\left(\mathrm{Q}_{2}\right)$ eşittir.

$$
\mathrm{Q}_{1}=\mathrm{Q}_{2} \quad \mathrm{Q}_{1}=\text { h.A. } \Delta \mathrm{T} \log
$$

Duman boruları logaritmik sıcaklık farkı değerlerinin bulunmasında Şekil 4.'de ki hesaplamalardan ve Denklem (3)'den faydalanılmıştır.

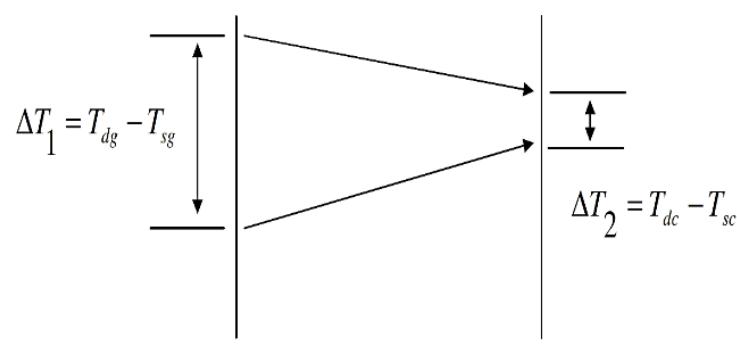

Şekil 4. Logaritmik sıcaklık farkı

Şekil 4.'de; $\mathrm{T}_{\mathrm{dg}}=$ Dumanın buruya giriş sıcaklığı (Ön sandık sıcaklı̆̆ı), $\mathrm{T}_{\mathrm{dc}}=$ Dumanın burudan çıkış sıcaklığı (Arka sandık sıcaklığı), $\mathrm{T}_{\mathrm{sg}}=$ Suyun kazana giriş sıcaklığı, $\mathrm{T}_{\mathrm{sc}}=$ Suyun kazandan çıkış sıcaklığı olarak verilmektedir.

Logaritmik sıcaklık farkı ise Denklem (3) yardımı ile hesaplanmıştır. 


$$
\Delta \mathrm{T}_{\log }=\frac{\Delta \mathrm{T}_{1}-\Delta \mathrm{T}_{2}}{\ln \left(\frac{\Delta \mathrm{T}_{1}}{\Delta \mathrm{T}_{2}}\right)}
$$

Denklem (2) de h ısı tasınım katsayısını, A akısın geçtiği borunun yan yüzey alanını(1sıl alanını) göstermektedir. Boru içindeki suyun 1sı miktarı $\left(\mathrm{Q}_{2}\right)$, Denklem (4) yardımı ile bulunur.

$$
\mathrm{Q}_{2}=\dot{\mathrm{m}}_{\mathrm{su}} \mathrm{C}_{\mathrm{p}_{\mathrm{su}}}\left(\mathrm{T}_{\mathrm{sg}}-\mathrm{T}_{\mathrm{sc}}\right)
$$

Denklem (4)'de ṁं elde edildikten sonra enerji bilânçosu ile ortalama isı transfer katsayısı hesaplanır. Denklem (5) yardımıyla kazanılan ısının yüzey alanındaki sıcaklık farkından dolayı oluşan ısıya eşitlenmesiyle h bulunur.

$$
\begin{aligned}
& \mathrm{Q}_{1}=\mathrm{Q}_{2} \\
& \text { h.A. } \Delta \mathrm{T}_{\log }=\dot{\mathrm{m}}_{\mathrm{su}} \mathrm{C}_{\mathrm{p}_{\mathrm{su}}}\left(\mathrm{T}_{\mathrm{sg}}-\mathrm{T}_{\mathrm{sc}}\right)
\end{aligned}
$$

Denklem (5)'te ki h katsayısı Denklem (6) yardımıyla hesaplanır.

$$
h=\frac{(\dot{V} . \rho)_{s u} C_{p_{s u}}\left(T_{s g}-T_{s c ̧}\right)}{\left(\pi D_{i} L\right) \cdot \Delta T \log }
$$

Denklem (6)'da $\dot{V}$ hacimsel debi, A duman borusu yan yüzey alanı, $\mathrm{D}_{\mathrm{i}}$ duman borusunun iç çapıdır. Denklem (6)'da bulunan h ısı transfer katsayısı (W/m²K) yardımı ile Nusselt sayısı Denklem (7) yardımıyla hesaplanır.

$$
N u=\frac{h L}{k}
$$

Denklem (7)'deki h 1sı tasınım katsayısı, L borunun uzunluğu ve k ise havanın ısı iletim katsayısıdır. Türbülatörler sayesinde Nu sayısındaki artış ısı transferindeki artısı olduğunu göstermektedir. Ancak türbülatörler yapısından dolayı akışa direnç oluşturmakta bu da basınç kaybının artmasına sebep olmaktadır. Bu amaçla ısıl kazanç oranın tespit etmek için net ısıl kazanç ve ek basınç kaybı miktarının belirlenmesi gereklidir. Isıl Kazanç oranını tespit etmek için Net 1sı kazancının ek basınç kaybına oranı olan ilgili Denklem (8) uygulanabilir [13].

$$
\frac{Q_{N I K}}{\Delta P_{K}}=\frac{Q_{T}-Q}{\Delta P_{T}-\Delta P} \cdot \frac{1000}{\dot{V} \cdot 9,81}
$$

Denklem (8)'de Q Qürbülatörlü deneylerde aktarılan 1S1 miktarı, Q türbülatörsüz yapılan deneyde aktarılan 1Sı miktarıdır. $\mathrm{P}_{\mathrm{T}}$ türbülatörlü deneylerde oluşan basınç farkı, $\mathrm{P}$ türbülatörsüz deneylerdeki basınç farkını göstermektedir. $\dot{V}$ hacimsel debidir. Denklem (8) de boyutsuz 1 sıl kazanç değeri elde edilir.

Isı transferi analizinde türbülatörsüz deneye göre artış olduğunu görmek amacıyla Denklem (9) kullanılarak yüzde artışlar bulunmuştur.

$$
\% \text { Artma }=\frac{Q_{T}-Q}{Q}
$$

Denklem (9)'da $\mathrm{Q}_{\mathrm{T}}$ türbülatörlü deneylerde aktarılan 1S1 miktarını, Q türbülatörsüz yapılan deneylerde aktarılan ısı miktarını göstermektedir. Bu hesaplama deneylerin tüm sonuçlarına uygulanmış olup türbülatörsüz deneye göre türbülatör ile yapılan deneylerin sonuçlarında yüzde olarak artışlar elde edilmiştir. 


\subsection{Yapay sinir ăğ}

Yapay sinir ağları ya da kısaca YSA; insan beyninin çalışma sisteminin yapay olarak benzetimi çabalarının bir sonucu olarak ortaya çıkmıştır. YSA, belirli değerlere dayanarak, girdi alanında olan noktaları çıktı alanında olan eş noktalara belli bir fonksiyonla bağlamaktadır [14]. Yapay sinir ağları, örüntü tanıma, tahmin etme, sınıflandırma vb. geniş uygulama alanına sahiptir. Yapay sinir ağları, insanlara benzer olarak örnekler ile öğrenirler. Bu nedenle veri seti, eğitim ve test kümesi olarak iki kısma ayrılır [15].

Sistemde, yapay sinir ağları beş giriş ve bir çıkış olarak modellenmiştir. Türbülatör boyu $\left(\mathrm{T}_{\text {boy }}\right)$, Reynolds sayısı (R) değeri, Nusselt sayısı $(\mathrm{Nu})$ değeri, 1 sı transferi \% artı̧ $\left(\% \mathrm{Q}_{\mathrm{h}}\right)$, Isı kazanç / Basınç Kayıp oranı $\left(\mathrm{Q}_{\text {kaz }} / \mathrm{P}_{\text {kay }}\right)$ değerleri giriş bilgisi olarak alınmıştır. Çıkış bilgisi olarak basınç düşüşü $(\Delta \mathrm{P})$ kullanılmıştır. Toplam olarak 4 katmandan oluşan modelin girdi katmanı 5 girdi için 5 nöron, birinci gizli katman 1 nöron, ikinci gizli katman için 1 nöron ve çıktı katmanı ise sadece tek bir nöron içermektedir. Oluşturulan YSA modelinin yapısı Şekil 5'de verilmiştir.

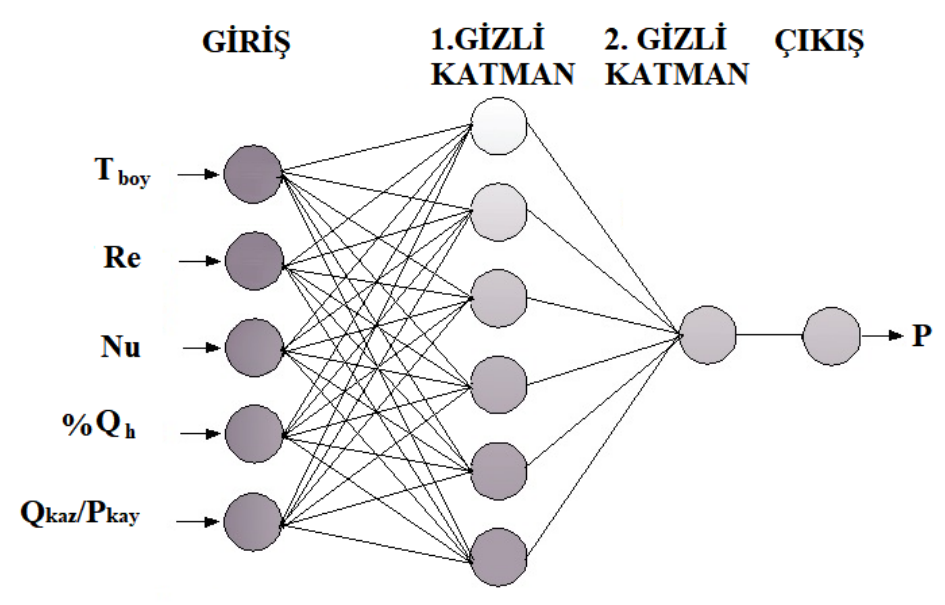

Şekil 5. YSA ağ yapısı şematik gösterimi

Basınç düşüşü değerlerinin yapay sinir ağı ile modellenmesinde MATLAB 2016a yazılımı kullanılmıştır. Bilgi kümesinde 120 adet giriş ve 24 adet çıkış bilgisi bulunmaktadır. Bu bilgilerden 100 tanesi eğitim işleminde kullanılmıştır. 44 tanesi ise test işleminde kullanılmıştır. Öğrenme algoritması olarak Feed Forward Back Propagation (ileri doğru beslemeli ve geriye yayılım) algoritması kullanılmıştır. Eğitim için Levenberg Marquardt algoritması kullanılmıştır. Elde edilen modelin geçerliliğini belirlemek için, ortalama mutlak hata (MAE), kök ortalama karesel hata (RMSE), bağıl mutlak hata (RAE) ve kök bağıl mutlak hata (RRAE) analizleri yapılmıştır. Hata analizlerinin formül ve parametreleri Tablo 1.'de verilmiştir.

Tablo 1. Hata Analizleri, Formülleri ve Parametreleri

\begin{tabular}{|c|c|c|}
\hline Hata Analizi & Formülü & Parametreler \\
\hline MAE & $\left|P_{1}-A_{1}\right|+\ldots \ldots+\left|P_{n}-A_{n}\right|$ & \multirow{7}{*}{$\begin{array}{l}\text { P: Tahmin Değeri } \\
\text { A: Gerçek Değer } \\
\text { n: Toplam Veri } \\
\text { P: Tahmin Değeri } \\
\text { A: Gerçek Değer } \\
\text { n: Toplam Veri } \\
\text { P: Tahmin Değeri } \\
\text { A: Gerçek Değer } \\
\text { A': Gerçek Değer Ort. } \\
\text { P: Tahmin Değeri } \\
\text { A: Gerçek Değer } \\
\text { A': Gerçek Değer Ort. }\end{array}$} \\
\hline & $n$ & \\
\hline RMSE & $\sqrt{\left(P_{1}-A_{1}\right)^{2}+\ldots \ldots+\left(P_{n}-A_{n}\right)^{2}}$ & \\
\hline & $\sqrt{n}$ & \\
\hline RAE & $\left|P_{1}-A_{1}\right|+\ldots \ldots+\left|P_{n}-A_{n}\right|$ & \\
\hline & $\overline{\left|A_{1}-A^{\prime}\right|+\ldots \ldots+\left|A_{n}-A^{\prime}\right|}$ & \\
\hline RRAE & $\sqrt{\frac{\left(P_{1}-A_{1}\right)^{2}+\ldots . .+\left(P_{n}-A_{n}\right)^{2}}{\left(\mid A_{1}-A^{\prime}\right)^{2}+\ldots . .+\left(A_{n}-A^{\prime}\right)^{2}}}$ & \\
\hline
\end{tabular}


Basınç düşüşü değerleri tahmini için kullanılan YSA modelinin parametleri ve yapısı Tablo 2.'de gösterilmiştir.

Tablo 2. YSA yapisı ve parametreleri

\begin{tabular}{ll}
\hline Gizli Katman Sayısı & 2 \\
Katmanlardaki Nöronlar & $6-1$ \\
Ağırlık Değerleri & Random \\
Aktivasyon Fonksiyonu & Logsig \\
Transfer Fonksiyonu & Tangent Sigmoid Transfer \\
Öğrenme Fonksiyonu & Feed-Forward Backprogpagation \\
\hline
\end{tabular}

\section{Bulgular}

Deneysel çalışma ve hesaplamalar sonucunda elde edilen değerlerden Re sayısı ile $\mathrm{Nu}$ sayısı arasındaki grafikler Şekil 6. da verilmiştir.

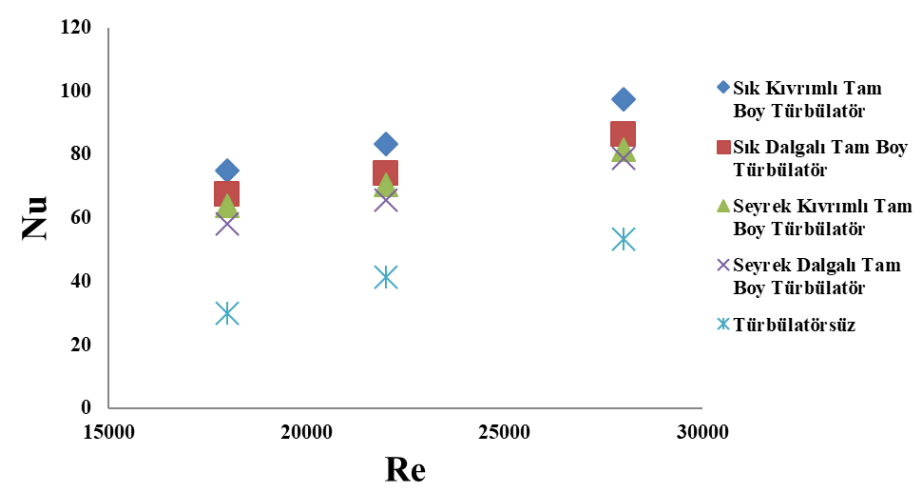

Şekil 6. Tam boy türbülatörlerin Re sayısının $\mathrm{Nu}$ sayısı ile değişimi

Şekil 6.' da görüldüğü gibi en yüksek Nusselt sayısı değerleri sık kıvrımlı tam boy türbülatörde elde edilmiştir. Şekil 6.' da tam boy kıvrımlı türbülatörle yapılan deneyler sonucu en yüksek Nusselt değeri 2800 Re da yapılan hesaplamalarda 97.5 olarak bulunmuştur. Kazan içerisinde türbülatör kullanarak 1sı transferinde iyileştirmeler sağlanmıştır. Isı transferindeki bu iyileşmenin basınç kaybı ile olan ilişkisi önemli olduğu için Re sayısının basınç farkı ile değişimi grafikleri Şekil 7.' de verilmiştir.

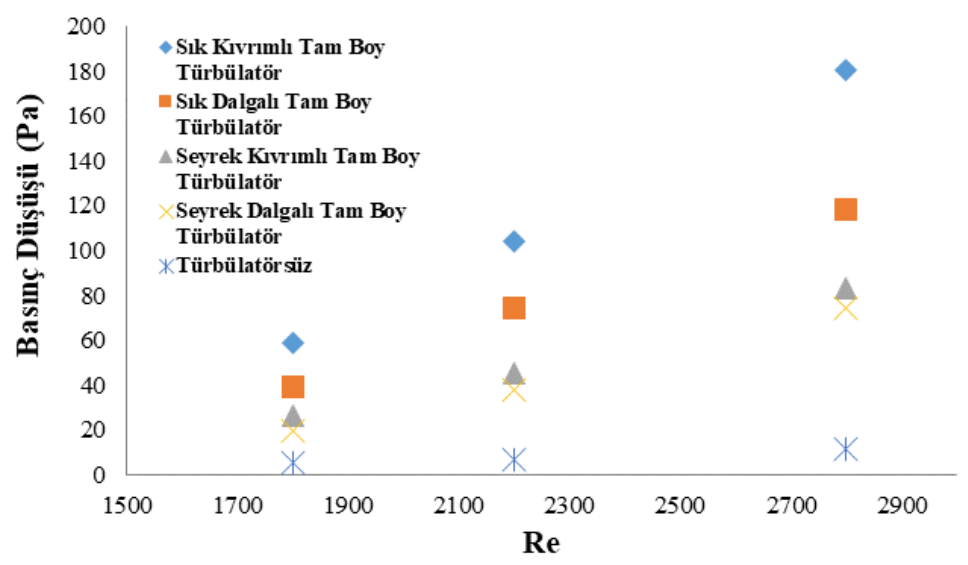

Şekil 7. Tam boy türbülatörlerin Re sayısının $\Delta \mathrm{P}$ ile değisimi.

Şekil 7.'de görüldüğü gibi sık kıvrımlı tam boy türbülatörde 2800 Re de en yüksek basınç kaybı $180.3 \mathrm{~Pa}$ olarak bulunmuştur. Denklem 3.5'te hesaplanan değerlerden net 1sı kazancının net basınç düşüşüne olan oranı ile Re sayısı değişimi Şekil 8.' de verilmiştir. 


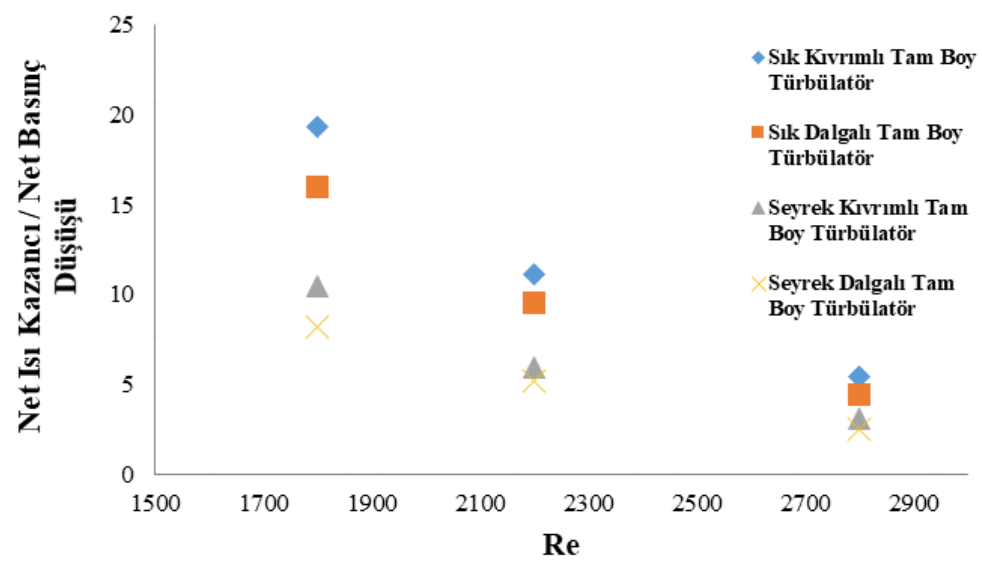

Şekil 8. Tam boy türbülatörlerde net ısı kazancı/ek basınç kaybı oranının Re sayısı ile değişimi

Türbülatörsüz yapılan deneyler ile tam boy türbülatör kullanılarak yapılan 1sı transferi karşılaştırması deneylerinin sonucu Tablo 3' de gösterilmiştir.

Tablo 3. Türbülatörlü deneydeki ısı transferinin türbülatörsüz deneye göre yüzde artış oranı

\begin{tabular}{|l|l|}
\hline Türbülatör Tipleri & Yüzde ısı transferi artış oranı \\
\hline Sık Dalgalı Tam Boy Türbülatör & $\% 63-\% 65$ \\
\hline Seyrek Dalgalı Tam Boy Türbülatör & $\% 44-\% 46$ \\
\hline S1k Kıvrımlı Tam Boy Türbülatör & $\% 82-\% 84$ \\
\hline Seyrek Kıvrımlı Tam Boy Türbülatör & $\% 53-\% 55$ \\
\hline
\end{tabular}

Yukarda Tablo 3’ de görüldüğü gibi, \% 84 lere kadar 1sı transferinde iyileşmeler sağlanmıştır. Bu orandaki artış, sık kıvrımlı tam boy türbülatörde görülmüştür. En az artış \% 44 ile seyrek dalgalı tam boy türbülatörde gerçekleşmiştir. Ancak en fazla basınç kaybı da yine sık kıvrımlı tam boy türbülatörde oluşmuştur. En az 1sı transferi ve en az basınç kaybı artısı seyrek dalgalı tam boy türbülatörde oluşmuştur. Deney setinden elde edilen basınç düşüşü değerleri için oluşturulan YSA tahminsel modeli için hesaplanan hata analiz değerleri Tablo 4.'de gösterilmiştir.

Tablo 4. YSA yapisı hata oranları

\begin{tabular}{ll}
\hline \multicolumn{2}{c}{ YSA hata oranları } \\
\hline MAE & 0.34 \\
RMSE & 0.671 \\
RAE & $18.5 \%$ \\
RRAE & $17.4 \%$ \\
\hline
\end{tabular}

MATLAB kullanılarak oluşturulan yapay sinir ağında elde edilen modelin mean squared error (MSE) hata analizi ile eğitim (train), doğrulama (validation) ve test kümelerine ilişkin hata performansları Şekil 9.'da gösterilmiştir. Şekil 9.'da Eğitim sonucunda her iterasyondaki eğitim, doğrulama ve test kümelerine ilişkin hata değerlerinin ne şekilde değiştiğini gösteren grafik yer almaktadır. Grafikte görüldüğg̈ üzere ağın eğitimi 1000 iterasyonda optimum sonuca ulaşmıştır. 


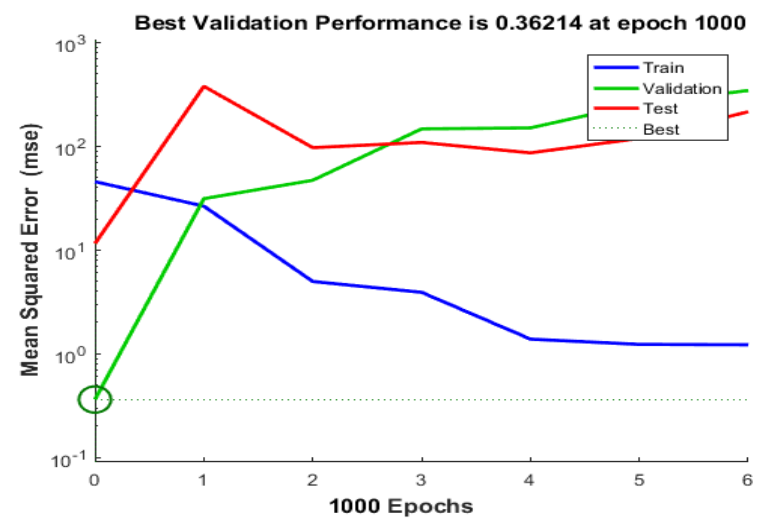

Şekil 9. Eğitim, doğrulama ve test kümelerine ilişkin hata performansları

MATLAB’ta eğitim (train), doğrulama (validation) ve test kümelerine ilişkin regresyon grafiği Şekil 10.'da gösterilmiş̧ir.
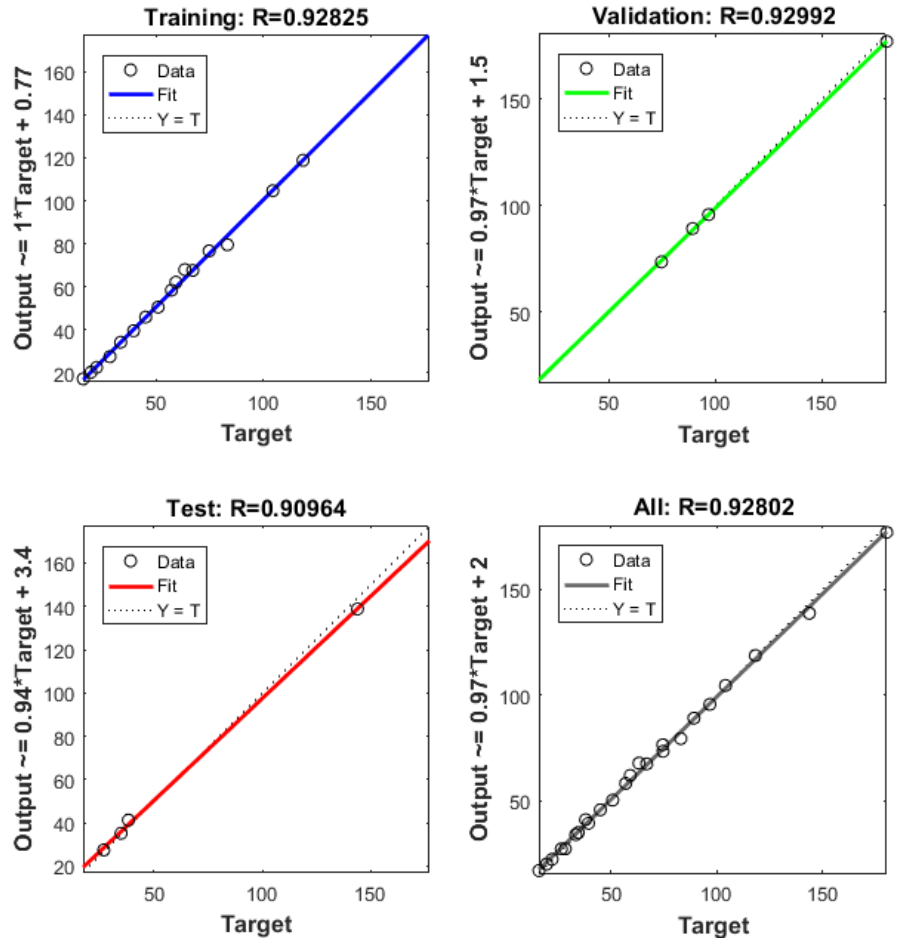

Şekil 10. MATLAB’ta öğrenme, doğrulama ve test kümelerine ilişkin regresyon grafiği

Şekil 10.'deki grafiğe göre en düşük değer 0.90964 olan test kümesine aittir. Buradan anlaşılacağı üzerine öğrenme işlemi büyük başarıyla gerçekleştirilmiştir.

Deney verileri ile elde edilen basınç düşüşü değerleri için YSA da tahminsel model oluşturulmuştur. Elde edilen tahminsel basınç düşüşü değerleri ile hesaplanan basınç düşüşü değerleri Şekil 11.'de gösterilmiştir. Şekil 11.'de YSA ile tahmin edilen basınç düşüşü değerleri, deneysel verilerle hesaplanan basınç düşüşü değerlerine çok yakındır. 


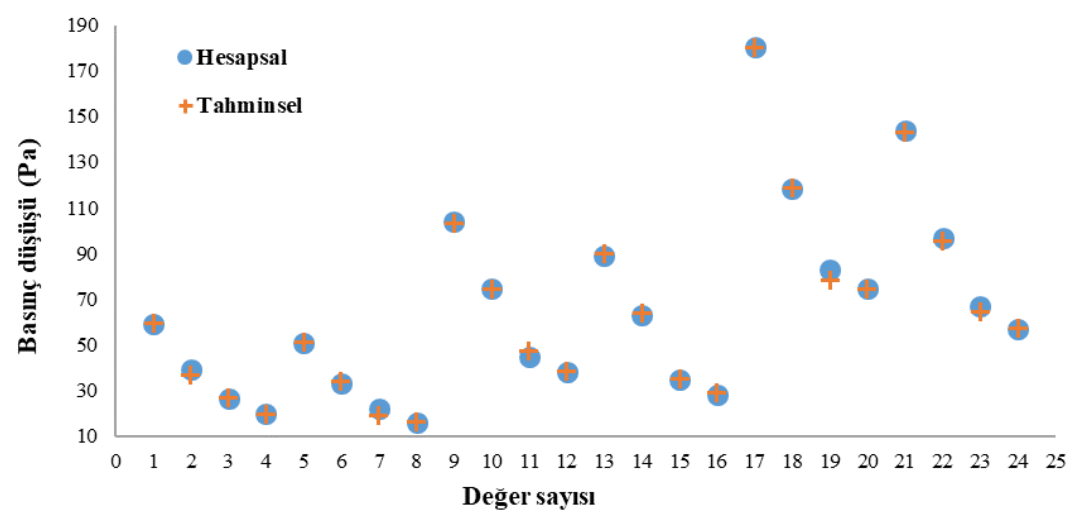

Şekil 11. Deneysel ve tahminsel basınç düşüşü değerleri

\section{Sonuçlar}

Türbülatörlü deneysel çalışmaların hepsinde türbülatörsüz deneylere göre 1sı transferi en az \% 44, en fazla \% 84 oranında artış sağlanmıştır. Aynı oranda basınç kayıplarının da arttığı görülmüşsür. Net ısı kazancının ek basınç kaybı oranı göz önüne alındığında tam boy türbülatörlerde sık kıvrımlı türbülatörün, en iyi sonucu verdiği görülmektedir. En iyi 1sı transferinin olduğu sık kıvrımlı tam boy türbülatörde dâhil olmak üzere tüm türbülatörlerde ısıl kazanç yanında basınç kaybındaki düşüşlerin az miktarda olduğu görülmektedir. Basınç düşüşü değerleri için YSA da elde edilen tahminsel modelin MAE (0.34) ve RMSE (0.671) hata analiz sonuçlarına göre başarılı bir tahmin yaptığı söylenebilir. Farklı tip türbülatör kullanılarak daha fazla veriler elde edilebilir ve bu veriler ile farklı hesapsal zeka yöntemleri kullanarak daha başarılı tahminsel modeller oluşturulabilir.

\section{Kaynaklar}

[1] Kahraman N, Sekmen U, Çeper B, Akansu S.O. Boru İçi Akışlarda Türbülatörlerın Isı Transferine Olan Etkisinin Sayısal İncelenmesi. Journal of Thermal Science and Technology 2008; 28(2).

[2] Sekmen U. Boru İçi Akışlarda Boru İçerisine Yerleştirilmiş Değişik Geometrideki Şekillerin Basınç Dağılımı, Hız Dağılımı Ve Isı Transferine Olan Etkisinin Araştırılması. Yüksek Lisans Tezi, Erciyes Üniversitesi, Kayseri, 2006.

[3] Sparrow E.M, Chaboki A. Turbulent Fluid Flow and Heat Transfer in a Circular Tube. ASME Journal of Heat Transfer 1984; 106, 766-773.

[4] Verma T.N, Nashine P, Singh D.V, Singh T.S, Panwar D. ANN: Prediction of an experimental heat transfer analysis of concentric tube heat exchanger with corrugated inner tubes. Applied Thermal Engineering 2017; 120, 219-227.

[5] Neuber A. Finite Rate Chemistry and NO Molefraction in Non-Premixed Turbulent Flames. Combustion and Flame 1998; 113, 198-211.

[6] Çakmak G, Yıldız C. Konsantrik ısı değiştirgeçlerine yerleştirilen enjektörlü elemanların optimizasyonu, F.Ü. Fen ve Mühendislik Bilimleri Dergisi 2003; 15(4),589-600.

[7] Lozza G, Merlo U. An Experimental investigation of Heat Transfer and Friction Losses of Interrupted and Wavy Fins for Fin-And-Tube Heat Exchangers. International Journal of Refrigeration 2001; 24, 409-416.

[8] Yıldız C, Biçer Y, Pehlivan D. Effect of Twisted Strips on Heat Transfer and Pressure Drop in Heat Exchanger. Energy Conversion \& Management 1998; 39, 331-336.

[9] Zaherzadeh N.H, Jagadish B.S. Heat Transfer in Decaying Swirl Flows, Int. J. Heat Mass Transfer 1975; 18(7) ,941-944.

[10] Moya-Rico J.D, Molina A.E, Belmonte J.., Tendero J. C, Almendros-Ibáñez J.A. Characterization of a triple concentrictube heat exchanger with corrugated tubes using Artificial Neural Networks (ANN). Applied Thermal Engineering 2019; 147, 1036-1046.

[11] Yılmaz T. ve Ayhan T. Birbirleriyle Bağlantılı Daralan -Genişleyen Kanallarda Isı Transferi, Isı Bilimi ve Tekniği 4. Ulusal Kongresi 1983; 133-149.

[12] Kakaç S. Isı İletimi, ODTÜ Mühendislik Fakültesi Yayınları, Yayın No: 52, Ankara, 1987.

[13] Çakmak G. Boru Girişinde Enjektörlü Türbülans Üreticisi Bulunan Isı Değiştirgeçlerinde Isı Transferinin ve Basınç Düşüşünün İncelenmesi, Yüksek Lisans Tezi. F.Ü. Fen Bilimleri Enstitüsü, Elazığ, 2000.

[14] Özdemir M.B, Aktaş M, Şevik S, Khanlari A. Modeling of a convective-infrared kiwifruit drying process. International Journal of Hydrogen Energy 2017; 28, 18005-18013.

[15] Teti R, Jemielniak K, O'Donnell G, Dornfeld D. Advanced monitoring of machining operations. CirpAnnalsManufacturing Technology 2010; 59, 717-739. 